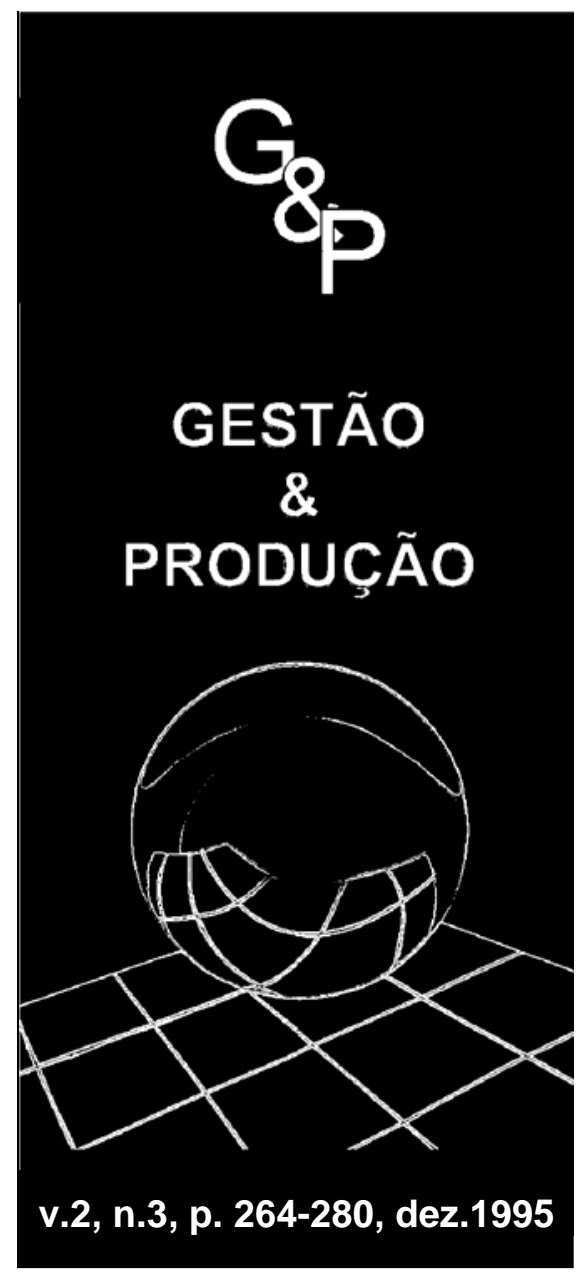

\title{
MODELO ECONÔMICO DE EMPRESA SUCROALCOOLEIRA
}

\begin{abstract}
Israel Brunstein
Professor Titular do Departamento de Engenharia de Produção da Escola Politécnica da Universidade de São Paulo Av. Prof. Almeida Prado, Trav.2, n 128 - 2 andar Cidade Universitária - São Paulo - S.P. CEP 05508-900 - Fone (011) 818-5363
\end{abstract}

Eduardo Heiji Tomiya M.Sc. e Doutorando do Departamento de Engenharia de Produção da Escola Politécnica da Universidade de São Paulo CTC/CTET - Caixa Postal 162 - CEP 13400-970 Fone (0194) 29-8287 - Fax (0194) 29-8388 - Piracicaba - S.P.

\section{Resumo}

O presente trabalho apresenta uma proposta de modelo econômico de empresa do setor sucroalcooleiro. O modelo apresentado foi adaptado do Modelo Econômico de Processos com Produção de Produtos Conjuntos. Acrescenta-se a utilização de elementos da Teoria da Decisão ao modelo, mediante utilização da Simulação Monte Carlo de variáveis externas relacionadas a preços e parâmetros de produtividade da fase agrícola. Os resultados foram analisados com base no critério da dominância estocástica.

\section{Palavras-chave: Modelo Econômico de Empresa, Agribusiness, Sistema de Produção de Produtos Conjuntos, Análise econômica de investimentos em pro- cessos produtivos, Simulação de sistemas, Teoria da Decisão.}

\section{Introdução}

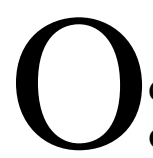

presente trabalho originou-se de diversas perguntas que hoje deixam o empresário do setor sem uma resposta clara, como por exemplo:

1. QUAL A RENTABILIDADE ECONÔMICA DE UM PROJETO DE FERTIRRIGAÇÃO? Um exemplo do processo de fertirrigação consiste na aplicação de um resíduo industrial, no caso a vinhaça, em propriedades da usina. Se por um lado existe um investimento para a aplicação do resíduo, por outro lado existe um aumento de produtividade do canavial. Essa produtividade adicional obviamente aumentará a produção de açúcar e álcool, alterando o plano de produção das fases agrícola e industrial. A resposta para tal questão 
poderia ser obtida com um modelo de empresa que considerasse a abordagem sistêmica da cadeia produtiva.

2. QUAL A RENTABILIDADE ECONÔMICA DE AQUISIÇÃO DE NOVOS CAMINHÕES CANAVIEIROS? Com a aquisição de novos modelos de caminhões de cana, em algumas situações o custo unitário de transporte diminuirá. Um aspecto normalmente não considerado em análises econômicas desta natureza é o que denominamos de flexibilidade de colheita. $\mathrm{O}$ plano do colheita é realizado baseado na obtenção do máximo de teor de sacarose obtido na cana das fazendas. Em determinadas ocasiões, a restrição de transporte de cana é ativa. O aumento do número de caminhões, neste caso, aumentaria a qualidade da matéria prima entregue, aumentando portanto a produção de açúcar e álcool da empresa. A resposta para esta questão necessitaria de um modelo que, assim como o mencionado no caso da pergunta 1, analisasse a cadeia produtiva com a abordagem sistêmica.

3. MUITAS ANÁLISES DE EMPRESA SÃO BASEADAS EM ESTIMATIVAS DE PARÂMETROS CLIMÁTICOS E ECONÔMICOS MÉDIOS. EM UMA ANÁLISE ECONÔMICA, ESPECIALMENTE NA COMPARAÇÃO ECONÔMICA, TAL TRATAMENTO NÃO PODERIA CAUSAR DIVERSOS PROBLEMAS? Este aspecto com certeza faz com que a atividade do analista econômico de empreendimentos relacionados ao setor sucroalcooleiro se torne uma das mais difíceis, já que freqüentemente este necessita de estimativas de preços e parâmetros de produtividade, de complexidade bastante elevada para a previsão em um horizonte de mais de um mês. A resposta a esta questão exigiria a utilização de um modelo econômico que não fosse determinístico, mas sim estocástico.
LOGIAS DE PROCESSO DISPONÍVEIS, QUAL SERIA A TECNOLOGIA PELA QUAL OBTERÍAMOS MAIOR VALOR AGREGADO? Normalmente, quando é solicitado ao analista econômico um estudo de viabilidade, já é pré-definida a área de negócios na qual se realizará a avaliação econômica, usualmente com base no feeling tecnológico ou com base em gargalos produtivos. Esta resposta só poderá ser dada por um modelo que incorpore um sistema de apuração de custos por atividades (Activity Based Costing) a um modelo econômico de empresa.

Com base nestas questões, que fazem parte do cotidiano do tomador de decisões de uma empresa do setor, observamos a necessidade de uma ferramenta que considere os aspectos mencionados, como:

Abordagem Sistêmica da cadeia produtiva.

Análise de Risco.

Integração com um sistema de custeio por atividades.

Considerando estas necessidades práticas, elaboramos o que denominamos de Modelo Econômico de Empresa Sucroalcooleira, que considera os dois primeiros aspectos acima mencionados, abrindo um bom caminho para o desenvolvimento do modelo completo contemplando o terceiro item em um próximo passo.

O Modelo Econômico determinístico foi adaptado do Modelo Econômico de Empresa de Processos de Produtos Conjuntos, um modelo que poderá ser utilizado para diversas empresas, especialmente ligadas ao setor agroindustrial, não se limitando ao setor sucroalcooleiro.

Na elaboração do Modelo Econômico Probabilístico de Empresa, foi elaborado um modelo que se utiliza de simulação de parânetros técnicos (pol \% cana e t.cana/ha.) e parâmetros econômicos (preços de produtos) com posterior análise dos resultados da simulação pelo método denominado Dominância Estocástica. 
s Usinas de Açúcar e Álcool no Brasil têm duas fases de processo, uma agrícola e outra industrial, formando os chamados sistemas agroindustriais. Um fluxo do processo produtivo sumarizado está ilustrado na figura 1.

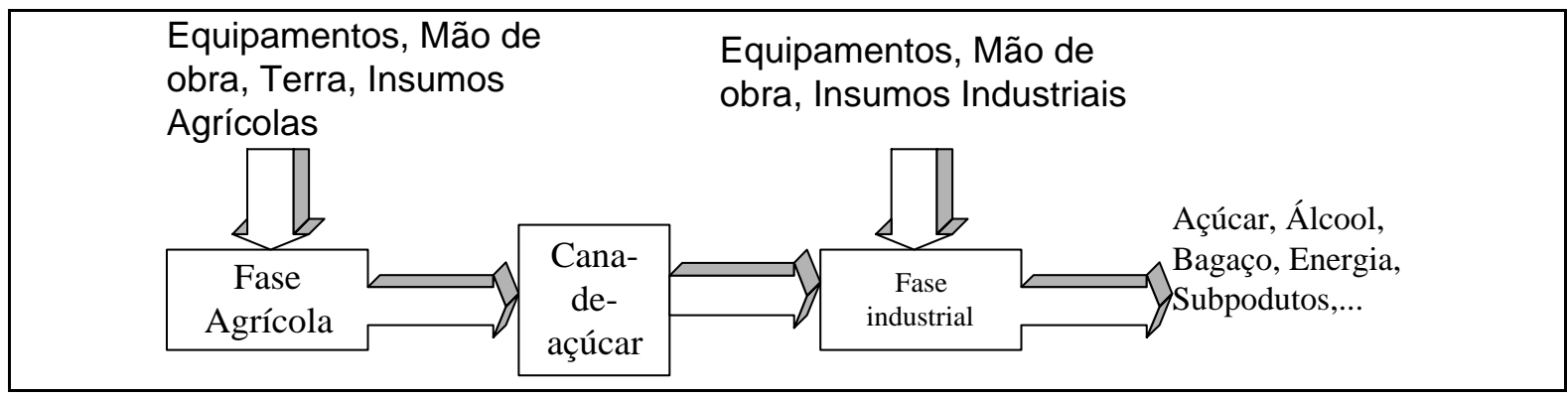

Figura 1. Fluxograma do Processo Agroindustrial

O Fluxograma mais detalhado dos materiais será ilustrado na figura 2 , na qual observamos a integração do Sistema agroindustrial. Observamos claramente que existem atividades de apoio às fazendas, caracterizadas na figura 2 como: máquinas agrícolas, sistemas de corte, carregamento e transporte de cana e insumos agrícolas. Posteriormente é ilustrado o processo industrial, iniciando com a moagem. $\mathrm{O}$ resultado da moagem é o caldo da cana e o bagaço. O primeiro pode ter várias utilizações, dentre elas a fabricação de açúcar, fabricação de álcool ou até mesmo a venda ín natura. O segundo pode ter diversas utilizações, dentre as quais: a queima para posterior geração de energia, a produção de papel e celulose, a produção de rações, entre outras.

Como alguns resíduos do processo temos a vinhaça, produzida na fase de fabricação de álcool e hoje aplicada em lavouras da própria usina, conforme é ilustrado na figura 2 , em que as áreas nas quais é feita a aplicação de vinhaça estão caracterizadas como Ambiente C.

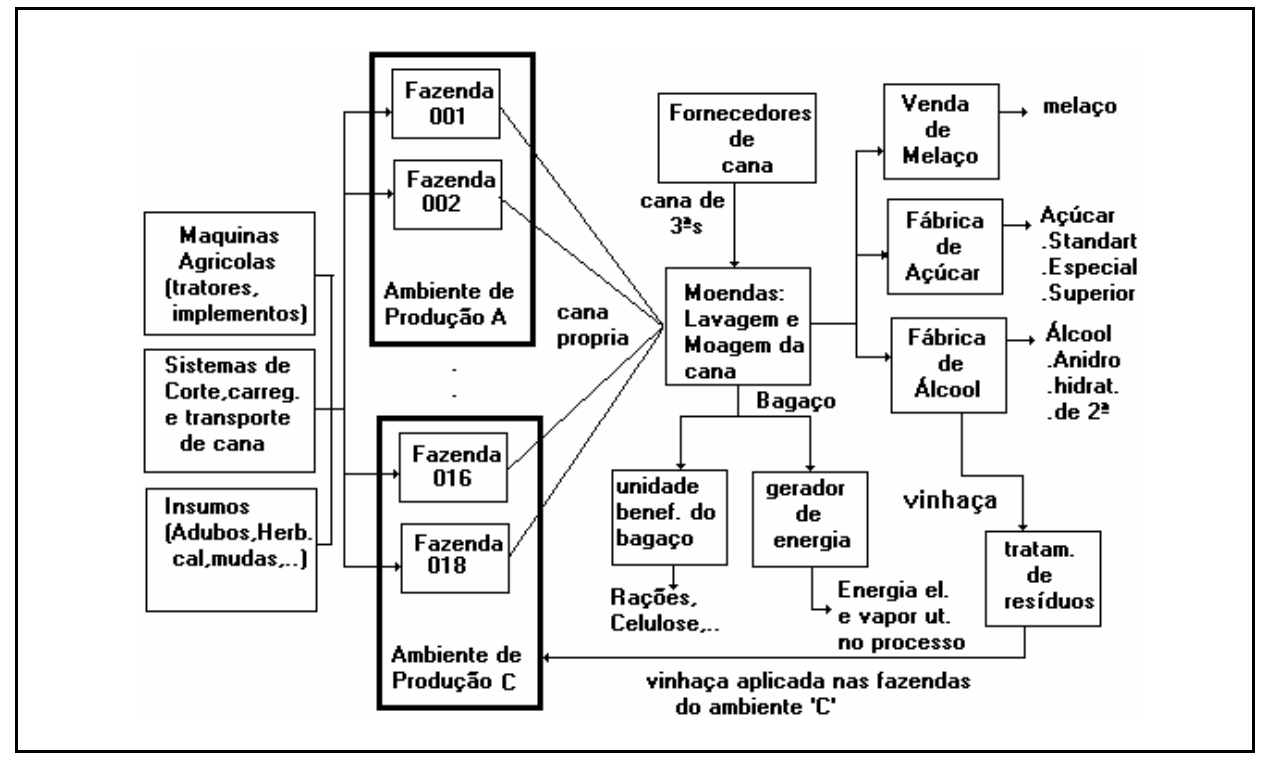

Figura 2. Fluxograma detalhado de materiais de uma Usina de açúcar e álcool 3. Modelo econômico determinístico de empresa 
Modelo econômico é uma adaptação do denominado Modelo econômico de empresa com processo de produção de produtos conjuntos (BRUNSTEIN, 1994), que será brevemente descrito a seguir.

\subsection{Modelo econômico de empresa de processo de produção de produtos conjuntos}

O processo de produção de produtos conjuntos pode ser entendido como o processo pelo qual se produz uma série de produtos que posteriormente serão ou não submetidos a processamentos adicionais. Tais processamentos podem ser:
- Processamentos adicionais alternativos;

- Processamentos adicionais obrigatórios;

- Processamentos adicionais em multiplas opções.

A figura 3, a seguir, ilustra os três processamentos em questão:

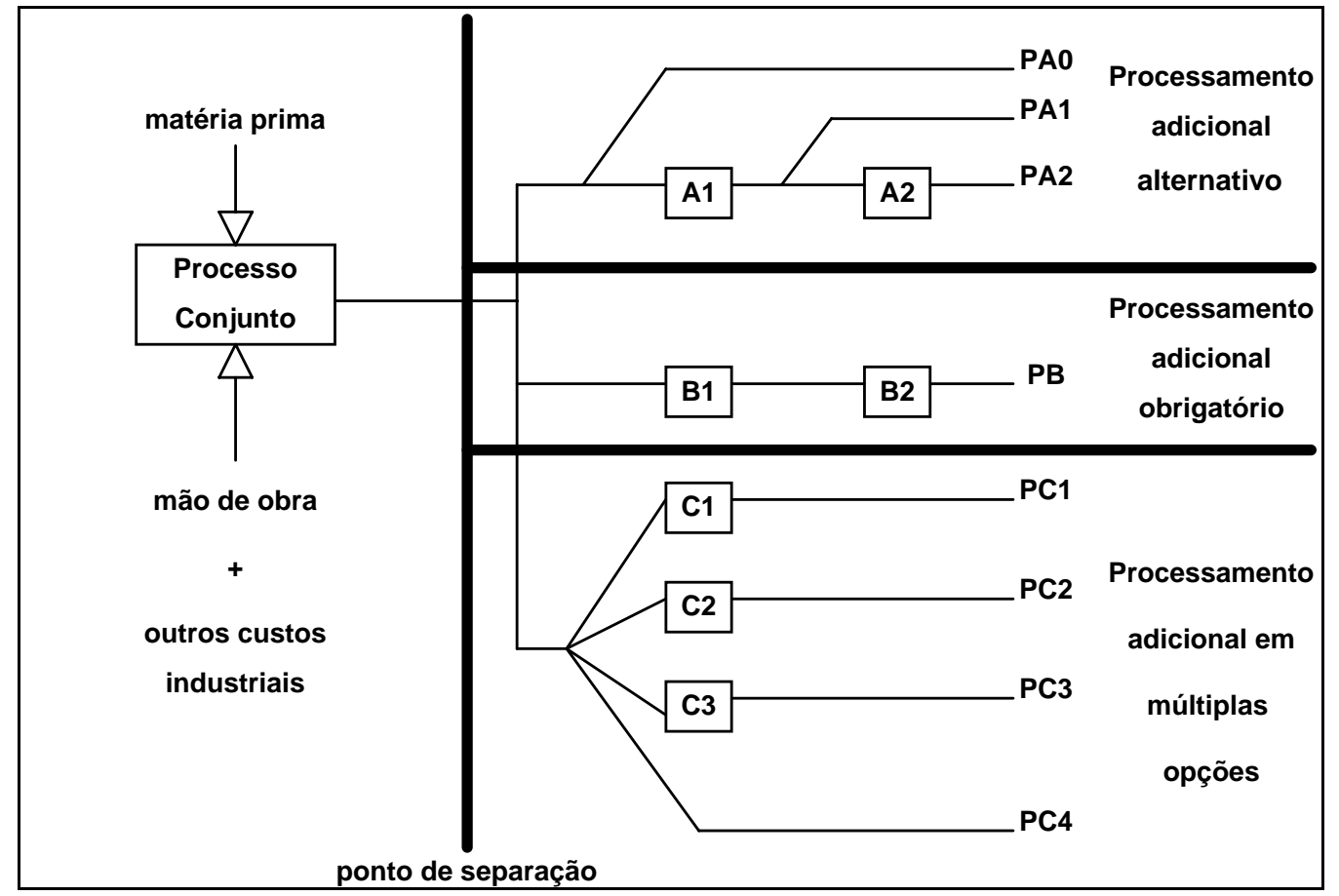

Figura 3. Conformações básicas do Processo de Produção de Produtos Conjuntos. Fonte: BRUNSTEIN (1994)

Tais configurações não são excludentes, ou seja, elas podem aparecer em uma mesma empresa simultaneamente. O modelo econô-mico de empresa começa com os produtos PA0, PA1 e PA2, que é a configuração pela qual temos um processamento adicional alternativo. $\mathrm{O}$ produto $\mathrm{PB}$ pode ser somente comercializado com dois processamentos, denominados de B1 e B2, por este motivo temos um processamento adicional obrigatório. O produto PC pode ser comercializado em diversos produtos: PC1, PC2, PC3 e PC4, cada um com um processamento diferenciado. Classificaremos o produto PC como produto com processamento em múltiplas opções. O Modelo Econômico de Empresas com o processo de produção conjunta é ilustrado na figura 4. Denominamos MBC = Margem Bruta de Contribuição = Receita Líquida Total - Custos Variáveis Totais e MSBC = Margem Semibruta de Contribuição = Margem Bruta de Contribuição - Custos Fixos Próprios.

Desde já devemos obsevar algumas grandes virtudes de tal modelo. A primeira delas é que não parte de nenhum dos famosos critérios de rateio, muito utilizados na contabilidade de custos. O sistema é se 
assim pode ser dito um sistema de custeio variável(direto), calculando o Resultado Econômico global da empresa.

Outra virtude do modelo está em associar a noção de valor não apenas aos produtos, como normalmente se faz nos sistemas tradicionais, mas também aos estágios do processo produtivo.

Decisões referentes ao mix produtivo também podem ser obtidas de maneira mais clara com tal modelo, determinando o resultado econômico global da empresa, e não de maneira isolada, ratificando-se aí a abordagem sistêmica.

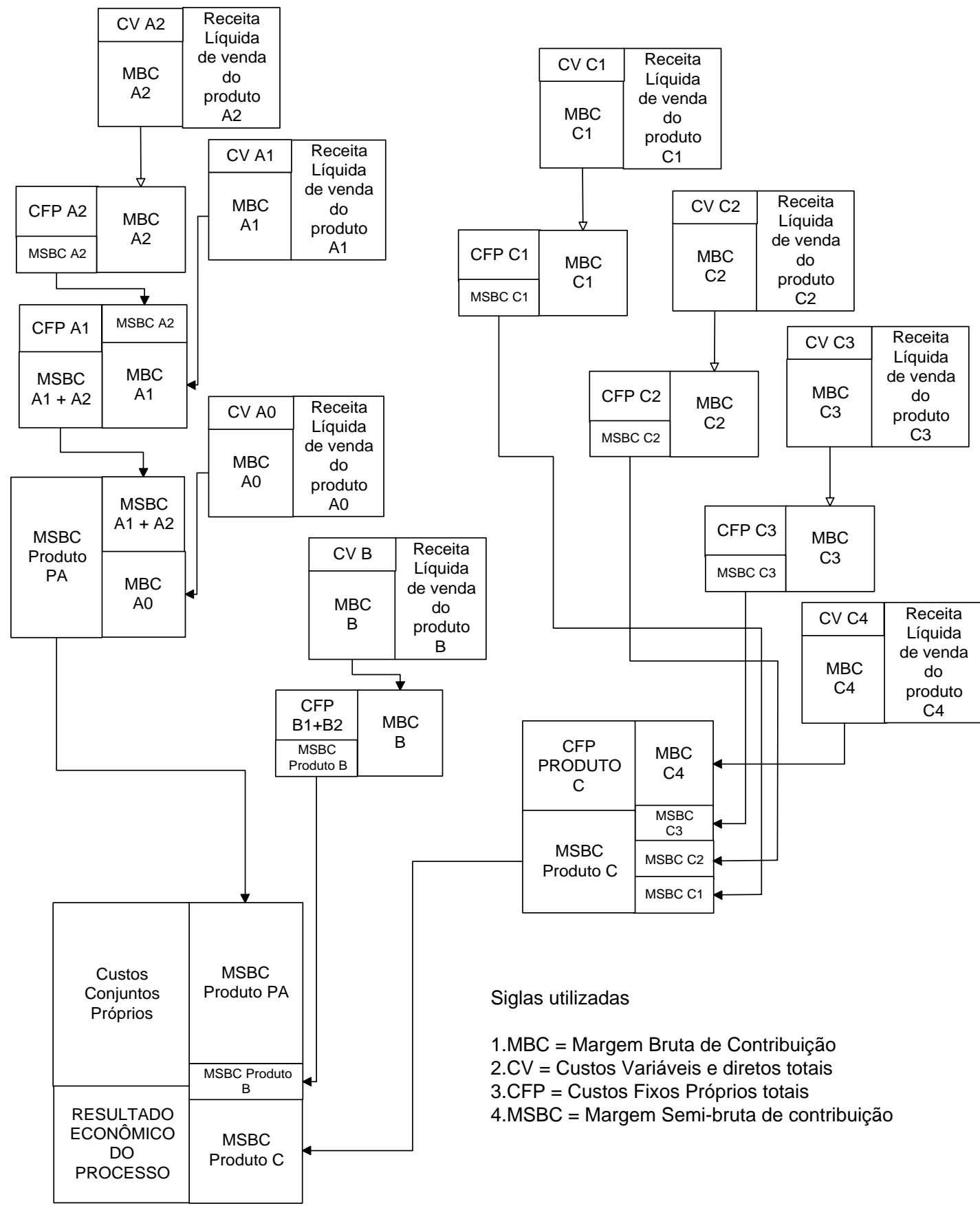

Figura 4. Modelo Econômico de Empresa de processo de produção conjunta para as conformações básicas apresentadas - Fonte: BRUNSTEIN (1994)

3.2. Adaptação do modelo econômico de empresa de processo de produção conjunta a uma usina de açúcar e álcool 
A caracterização do processo de uma usina de açúcar e álcool como um processo de produção de produtos comjuntos é ilustrada na figura 5, a seguir, na qual podemos observar um ponto de separação do processo a partir da fase de moagem de cana.

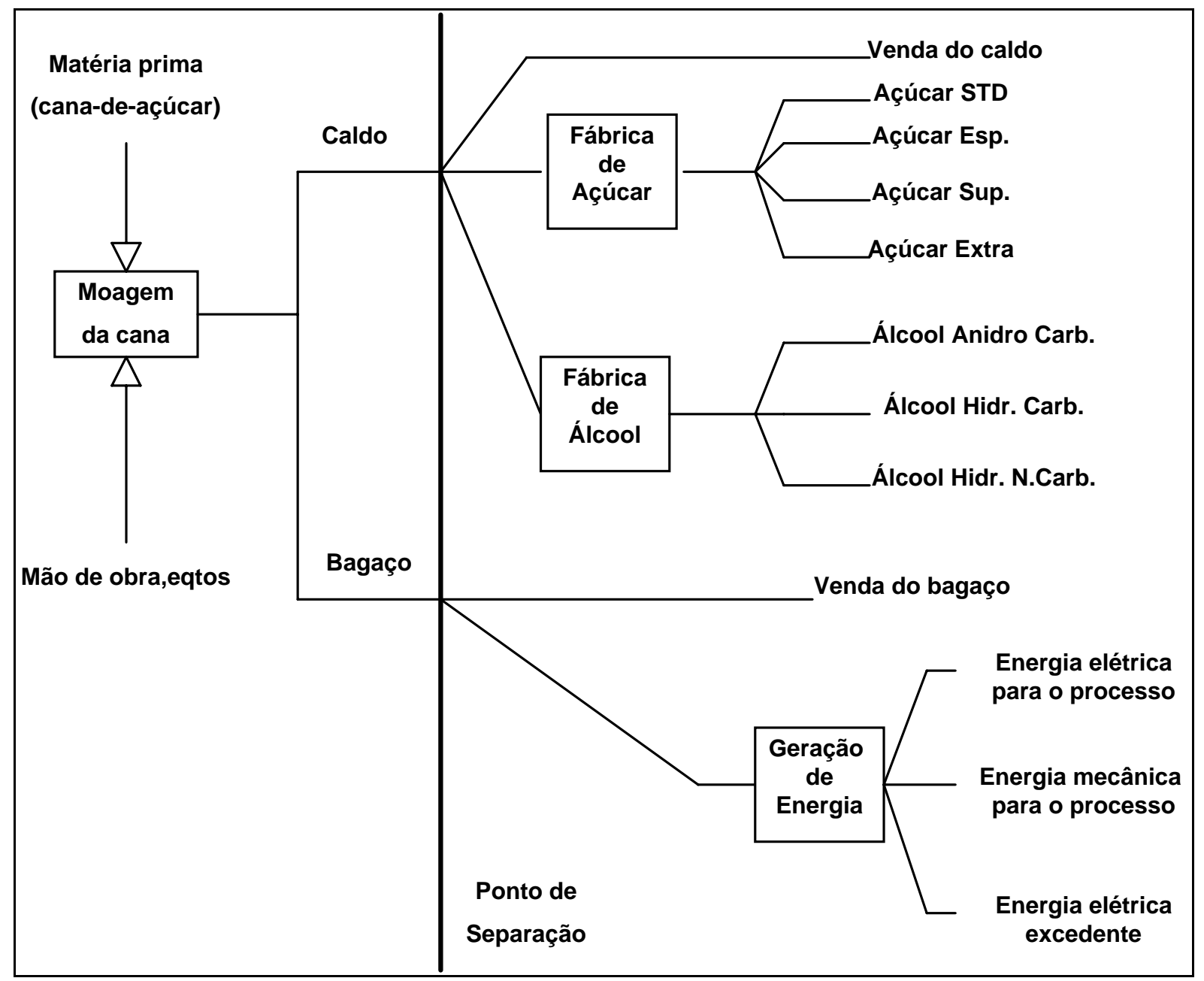

Figura 5. Caracterização do processo de produção da fase industrial de uma usina com processo de produção conjunto

\section{Modelo econômico da fase industrial}

O Modelo Econômico da fase industrial é ilustrado na figura 6. Cada uma das fases (Moagem, Fábrica de Açúcar, Fábrica de
Álcool e Geração de Energia) terá seus custos e receitas detalhados. 


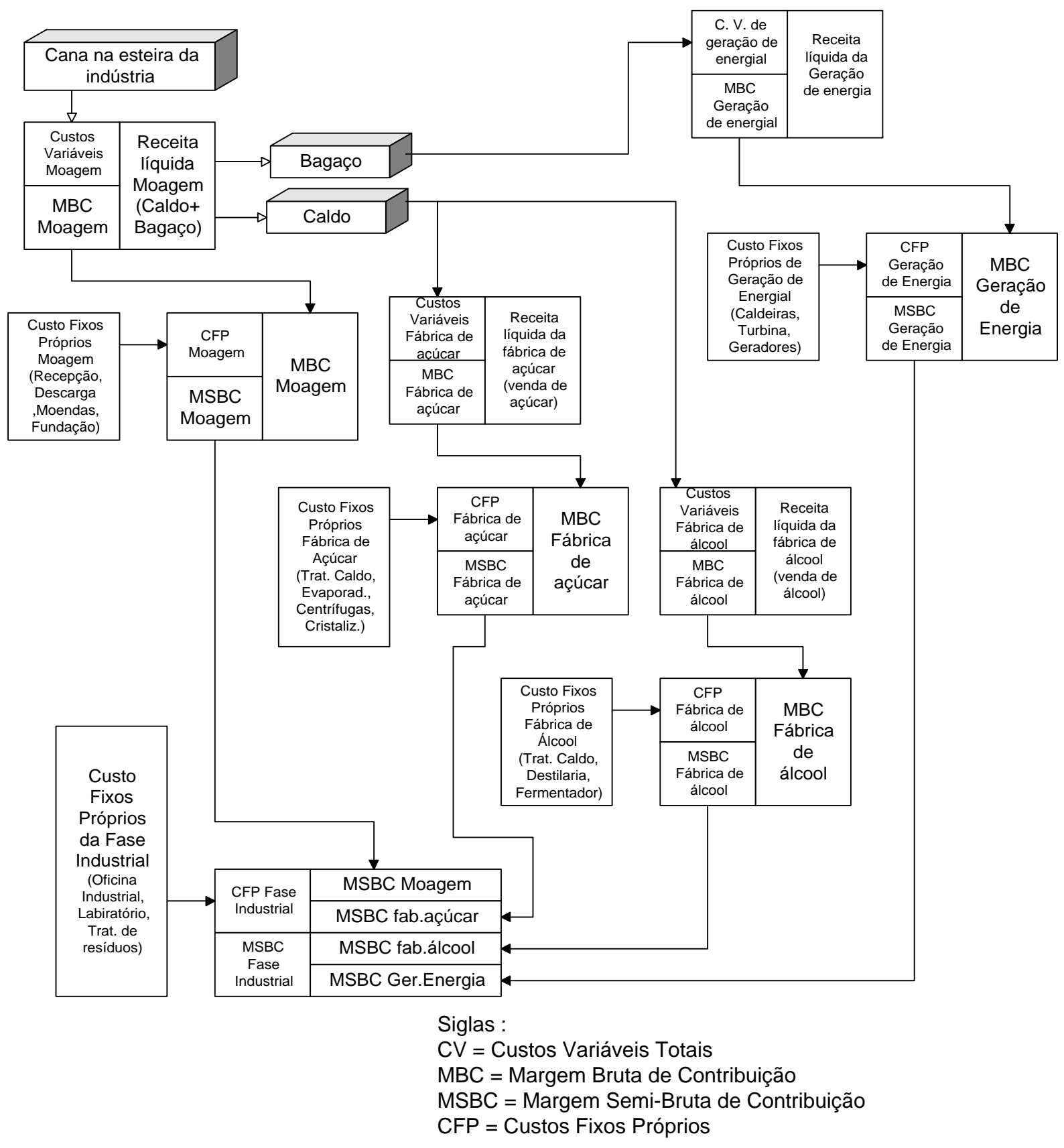

Figura 6. Resultado econômico da fase industrial

\section{Moagem de cana}

O primeiro estágio a ser analisado foi a moagem e extração de cana. Seus insumos básicos são: a Cana de açúcar de (procedência das fazendas próprias ou de fornecedores), a Mão de obra direta e Manutenções preventivas, ligadas à lubrificação dos equipamentos envolvidos no processo industrial, ilustrado na figura 6 .

Com base na margem bruta de contribuição e nos custos fixos próprios da fase de moagem de cana determinamos a margem semibruta de contribuição da fase de moagem de cana.

\section{Fábrica de Açúcar}

A análise da fábrica de açúcar partirá do pressuposto de que sua matéria prima principal será o caldo da cana, oriundo da fase de moagem da cana. É como se imaginássemos que a fábrica de açúcar compra tal insumo da fase de moagem de 
cana. Além do caldo, são custos variáveis da fábrica de açúcar a Mão de Obra Direta e outras drogas (Enxofre,...). Os componentes do Custo Fixo Próprio da fábrica de açúcar são equipamentos exclusivos do processo de fabricação de açúcar a partir do caldo (Evaporadores, Cozimento, Cristalizadores, Centrífugas, Secadores e Armazéns de Açúcar).

\section{Fábrica de Álcool}

A análise da fábrica de álcool também partirá do pressuposto de que sua matéria prima principal será o caldo da cana, oriundo da fase de moagem da cana. Analogamente à fábrica de açúcar, na fábrica de álcool os custos variáveis são, além do caldo, a Mão de Obra Direta e Insumos. Os componentes do Custo Fixo Próprio são equipamentos exclusivos do processo.

\section{Geradores de energia}

A análise da fase de geração de energia partirá do pressuposto de que sua matéria prima principal será o bagaço de cana, oriundo da fase de moagem da cana, analogamente à fábrica de açúcar e à fábrica de álcool. O custo associado a esta matéria prima é custo de oportunidade de venda da matéria prima in natura. Além do bagaço, o custo variável desta fase é composto pela mão de obra diretamente apropriada ao processo.

Os componentes do Custo Fixo Próprio são equipamentos exclusivos para 0 processo.

\section{Margem semibruta de contribuição da fase indústrial}

Com base na margem semibruta de contribuição das fases de moagem de cana, fábrica de açúcar, fábrica de álcool e geração de energia, determinaremos a margem semibruta de contribuição da fase industrial. Os Custos Fixos Próprios são compostos pelos que não são apropriáveis a nenhuma das fases anteriormente descritas, como por exemplo a oficina industrial. Este Departamento poderia, em um modelo clássico de sistema de custeio por absorção, ser rateado entre algumas das fases produtivas, mediante algum critério de rateio. Porém, no presente modelo, não existem os denominados critérios de rateio da contabilidade de custos. Somente consideraremos como custo, para cada fase, os custos próprios e diretos para cada operação, já que sempre trabalhamos com o resultado total, e não unitário da empresa. Sendo assim, compõem o Custo Fixo Próprio da fase industrial, além da Oficina Industrial, os Laboratórios da fase industrial, a balança, os desembolsos com tratamento de resíduos (Vinhaça, águas residuais), Obras Civís e Mão de Obra indireta.

\section{Modelo econômico de empresa da fase agrícola}

O modelo econômico da fase agrícola do processo, que avaliará a rentabilidade econômica desta fase, conforme é ilustrada na figura 7. 


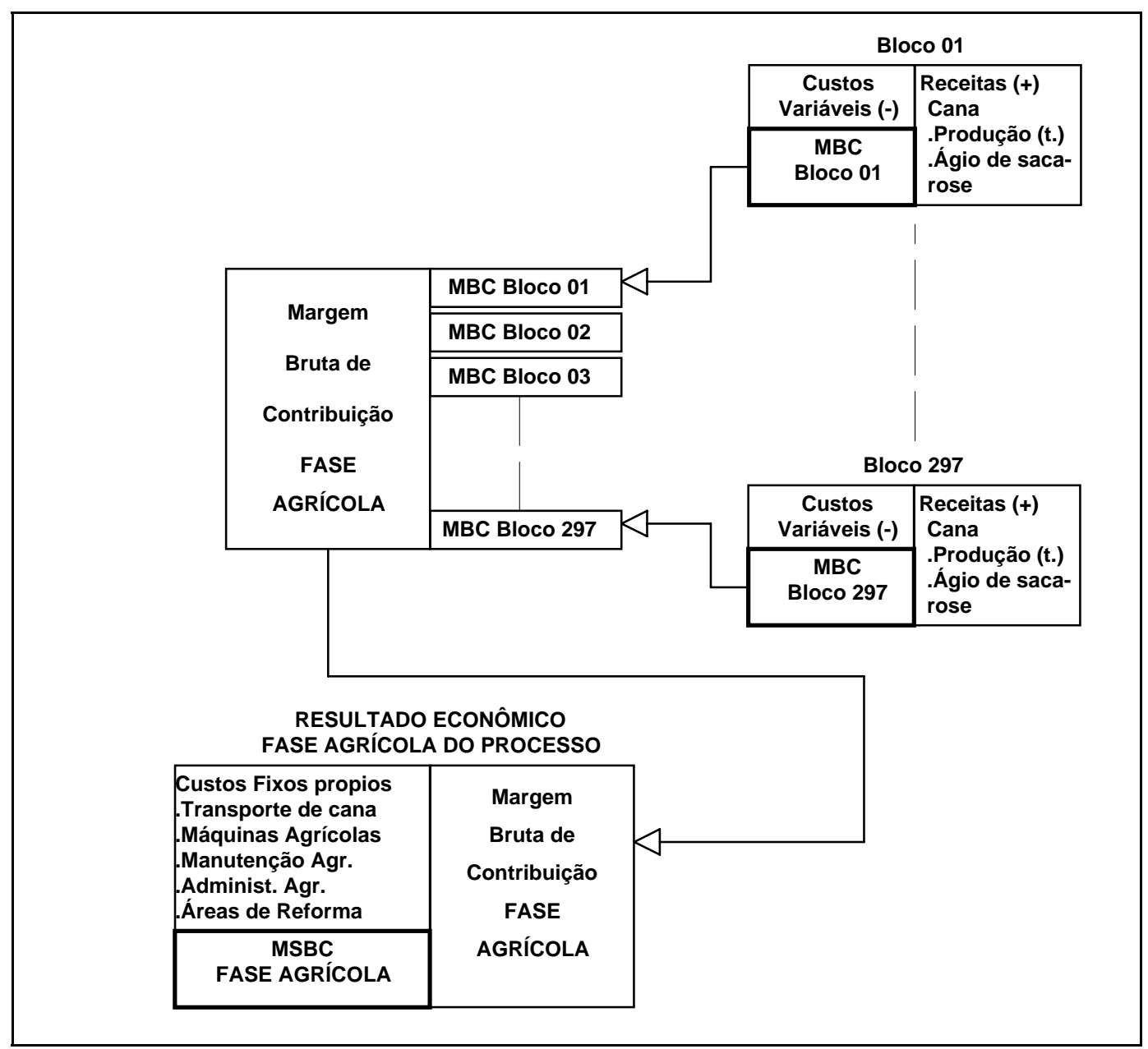

Figura 7. Resultado Econômico da Fase Agrícola

\section{Modelo econômico da fase agroindustrial}

Com base nos resultados econômicos próprios da agroindústria, obtivemos o obtidos nas fases agrícola e industrial do resultado econômico da fase agroindustrial, processo, subtraindo-se os custos fixos ilustrado na figura 8.

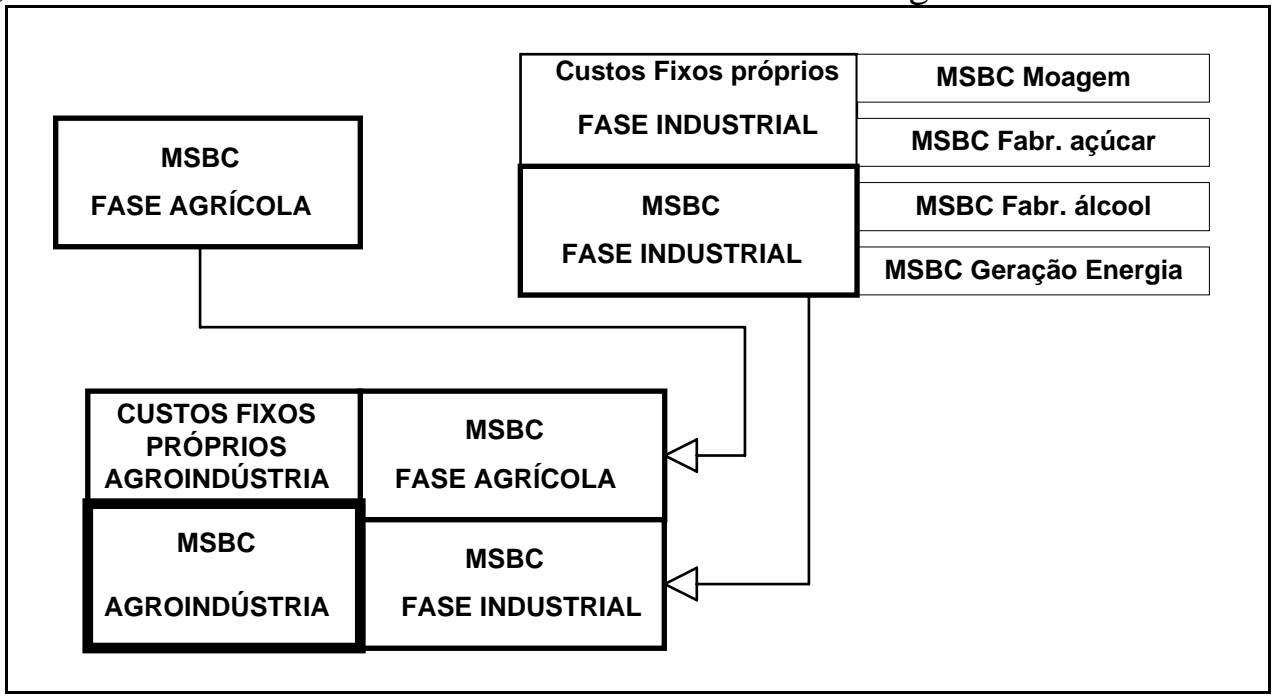

Figura 8. Resultado econômico da fase agroindustrial 
4. Avaliação econômica de um projeto de fertirrigação da Usina TESE - modelo determinístico

Situação atual (Alternativa defensora)

$\mathrm{P}$ rocessaremos o modelo econômico de empresa com parâmetros médios de preços e expectativas de produtividade em uma usina fictícia, criada pelo autor, a partir daqui denominada de Usina TESE, obtendo os resultados da tabela 1.

Tabela 1. Resultados técnicos e econômicos do modelo econômico determinístico de empresa Usina TESE-Situação Atual

\begin{tabular}{|l|c|}
\hline \multicolumn{1}{|c|}{ Itens } & Resultado \\
\hline RESULTADO AGROINDÚSTRIA (US\$/ANO) & 11.176 .055 \\
\hline RESULTADO AGRÍCOLA (US\$/ANO) & -1.957 .649 \\
\hline RESULTADO INDÚSTRIA (US\$/ANO) & 13.133 .704 \\
\hline . Resultado Moagem de cana (US\$/ANO) & 2.600 .102 \\
\hline . Resultado Fabricação de açúcar (US\$/ANO) & 1.978 .999 \\
\hline . Resultado Fabricação de álcool (US\$/ANO) & 8.827 .957 \\
\hline . Resultado Geração de energia (US\$/ANO) & 674.525 \\
\hline Produção de cana (t.cana) & 833.787 \\
\hline Produção de açúcar (t.açúcar) & 56.804 \\
\hline Produção de álcool (m3) & 61.826 \\
\hline Produção de energia elétrica (MWh) & 34.204 \\
\hline
\end{tabular}

\section{Situação Proposta (Alternativa desafiante)}

Processando-se o modelo econômico para a alternativa desafiante na Usina TESE, obtivemos os resultados técnicos e econômicos ilustrados na tabela 2 a seguir.

A rentabilidade econômica do empreen- dimento é analisada não somente em termos de resultados econômicos, como também em termos de parâmetros técnicos, analisando, conforme o objetivo inicial do trabalho, o impacto na cadeia produtiva como um todo.

Tabela 2. Resultados econômicos do projeto de ampliação de áreas com aplicação de vinhaça - Usina TESE

\begin{tabular}{|c|c|c|c|}
\hline & $\begin{array}{c}\text { Situação } \\
\text { Atual } \\
\text { (1) }\end{array}$ & $\begin{array}{c}\text { Situação Proposta } \\
\text { c/proj. fert. } \\
\text { (2) } \\
\end{array}$ & $\begin{array}{c}\text { Diferença } \\
\text { (2)-(1) }\end{array}$ \\
\hline RESULTADO AGROINDÚSTRIA & 11.176 .055 & \begin{tabular}{|l|}
11.526 .982 \\
\end{tabular} & 350.927 \\
\hline RESULTADO AGRÍCOLA & -1.957 .649 & -2.006 .212 & -48.563 \\
\hline RESULTADO INDÚSTRIA & 13.133 .704 & 13.533 .194 & 399.490 \\
\hline . Resultado Moagem de cana & 2600102 & 2.676 .611 & 76.509 \\
\hline Resultado Fabricação de açúcar & 1978999 & 2.059 .517 & 80.518 \\
\hline Resultado Fabricação de álcool & 8827957 & 9.044 .903 & 216.946 \\
\hline . Resultado Geração de energia & 674525 & 700.043 & 25.518 \\
\hline Produção de cana (t.cana) & 833787 & 853.624 & 19.837 \\
\hline Produção de Açúcar (t.açúcar) & 56804 & 57.952 & 1.148 \\
\hline Produção de álcool (m3) & 61826 & 63.250 & 1.424 \\
\hline Produção de Energia elétrica (MWh) & 34204 & 34.941 & 737 \\
\hline
\end{tabular}


$\mathrm{V}$

erificamos um elevado grau de incerteza nas variáveis de entrada do modelo, como política de preços e expectativas de produtividade, principalmente relacionadas à fase agrícola do processo. Este foi o motivo de realizarmos uma abordagem probabilística, analisando a decisão sob condições de incerteza, incorporando elementos da Teoria da Decisão para a análise desta questão. As variáveis que foram simuladas no caso são: pol \% cana (\% peso de sacarose na cana de açúcar), tonelada de cana por hectare (TCH) para cada bloco, preço da cana-de-açúcar, preço do açúcar e preço do álcool. A influência de cada variável de incerteza no desempenho econômico das fases (MSBC = Margem Semibruta de Contribuição = Margem de Contribuição - Custos Fixos próprios) é ilustrada na figura 9. As simulações foram realizadas utilizando-se o método Monte Carlo descrito em SHIMIZU(1975,1984). Para a realização da simulação utilizamos as funções estatísticas do Microsoft Excel Versão 4.0.

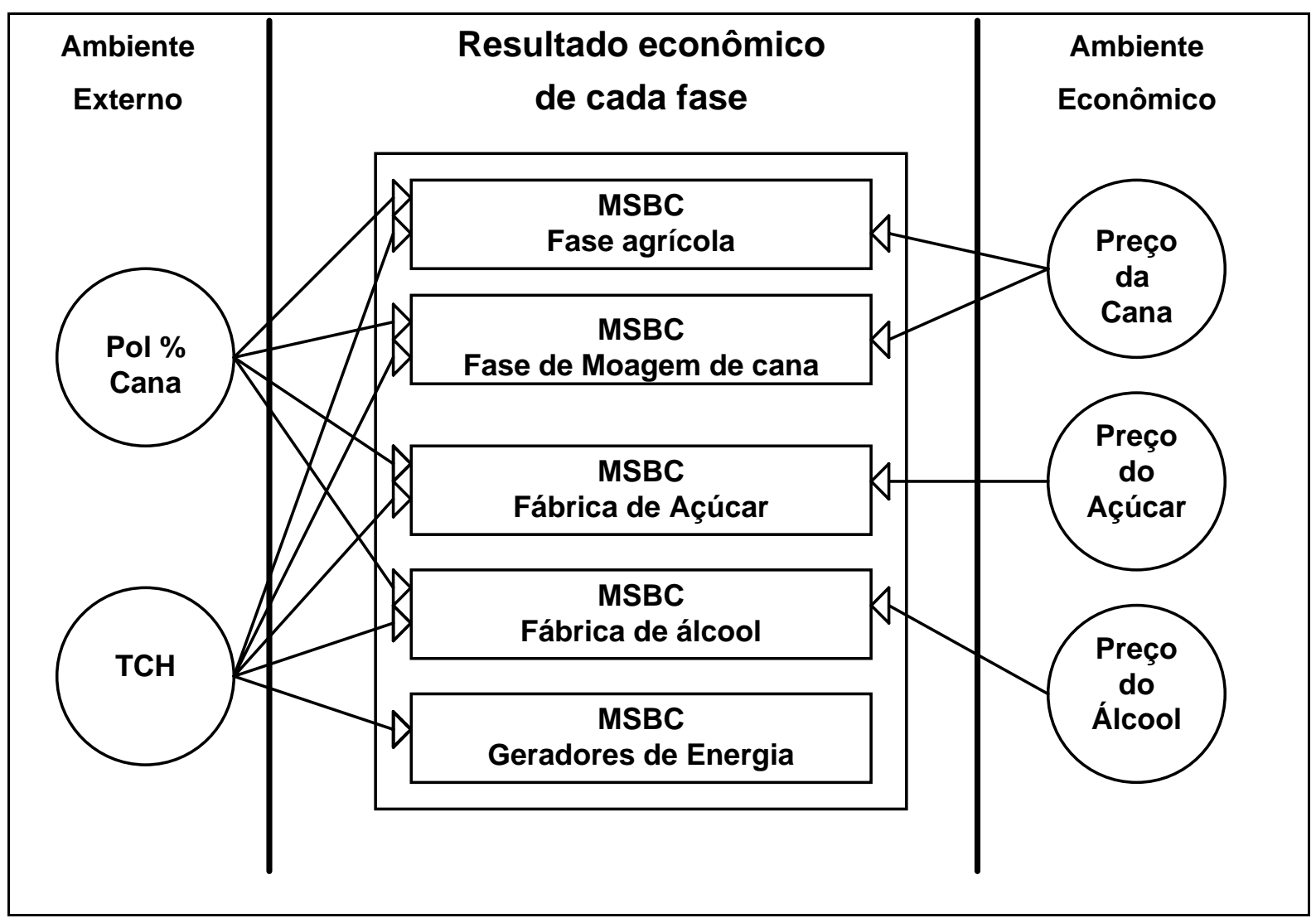

Figura 9. Influência de cada variável de incerteza no resultado econômico de cada fase do processo produtivo

Processando o modelo econômico aproximadamente 600 vezes para a situação atual (alternativa desafiante), obtivemos a distribuição de probabilidades do resultado agroindustrial da Usina TESE, ilustrada na figura 10 . 


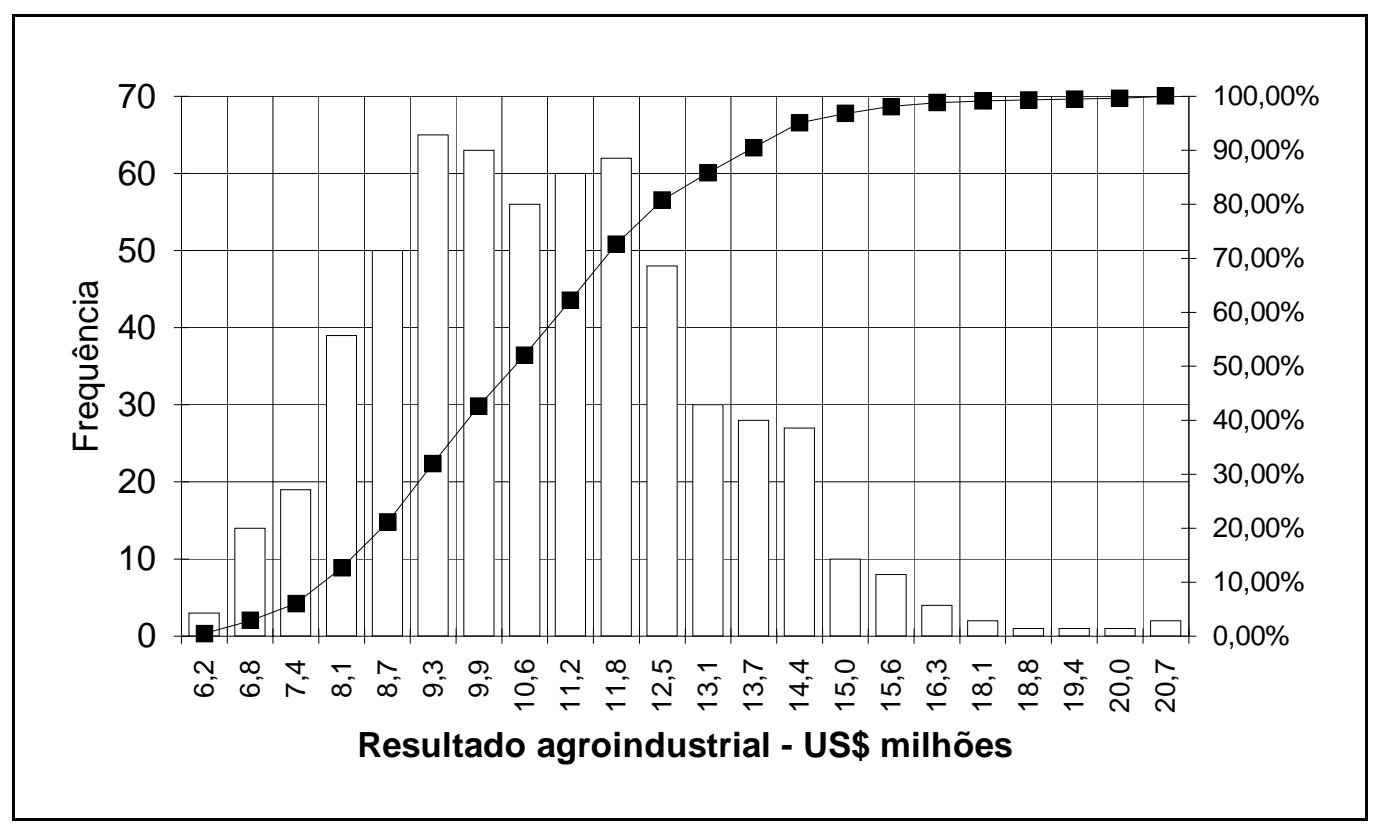

Figura 10. Distribuição de probabilidades do resultado econômico agroindustrial - Usina TESE - Situação atual - Fonte: 593 simulações do modelo econômico

Processando o modelo econômico para a alternativa com ampliação das áreas com aplicação de vinhaça aproximadamente 600 vezes, obtivemos a distribuição de probabilidades do resultado econômico da fase agroindustrial, ilustrada na figura 11.

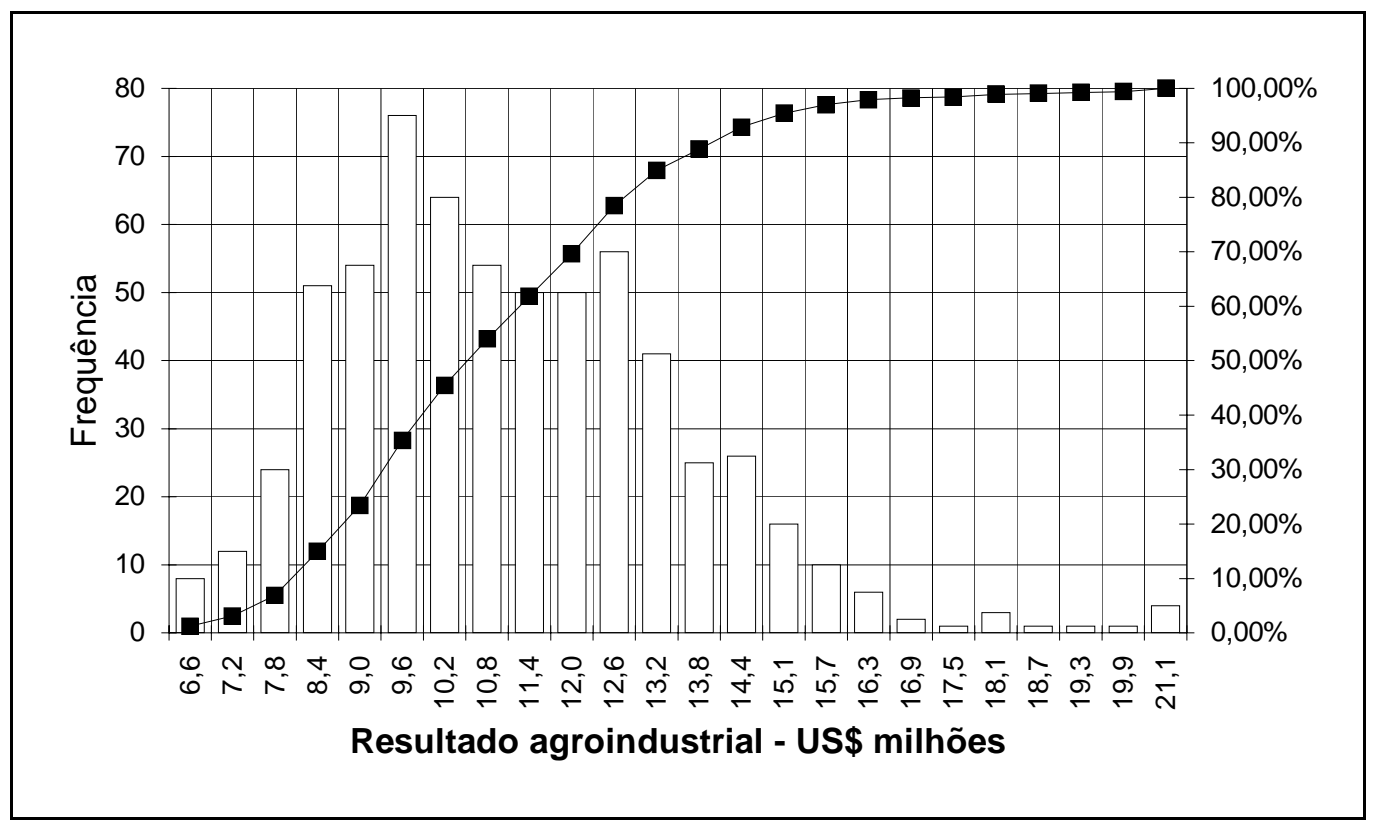

Figura 11. Distribuição de probabilidades do resultado econômico agroindustrial - Usina TESE - Situação com projeto de fertirrigação

Fonte: 600 simulações do modelo 
Para a análise estocástica dos resultados da simulação, utilizamos os critérios da Dominância Estocástica de Primeiro, Segundo e Terceiro Grau, utilizada em diversos trabalhos, principalmente relacionados à engenharia agronômica (HADAR \&
RUSSEL, 1969; GARCIA \& CRUZ, 1979; PACHECO, 1985; SOUZA, 1990).

Obtivemos, conforme ilustra na figura 12, a distribuição de freqüência acumulada dos resultados econômicos da fase agroindustrial das duas alternativas.

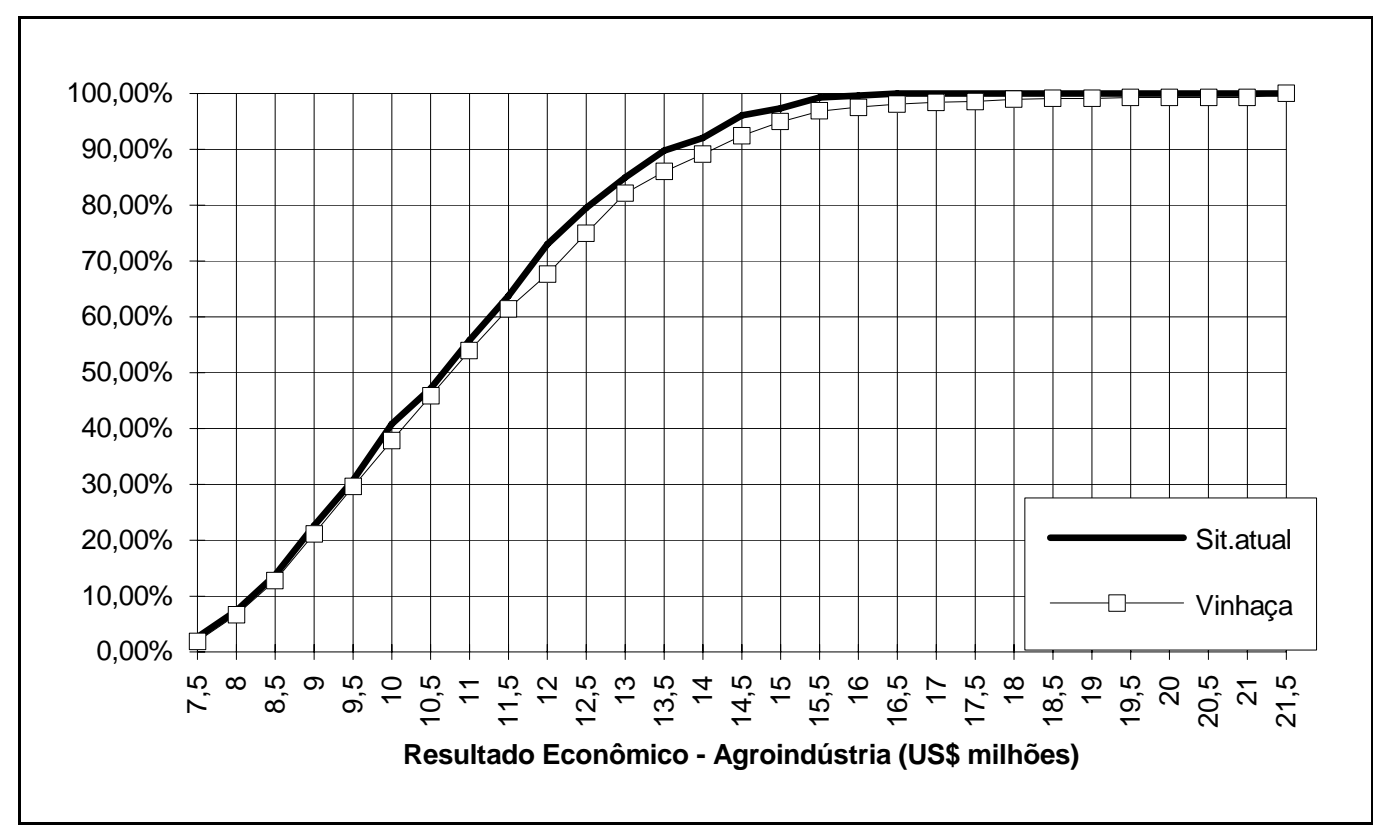

Figura 12 - Distribuições de freqüência acumulada do resultado econômico agroindustrial Usina TESE - Fonte: Simulações realizadas no estudo.

Segundo o critério da dominância estocástica, se a distribuição acumulada de uma alternativa tiver dominância em todos os pontos da análise (para qualquer ponto da coordenada y, a alternativa dominante possui resultado econômico maior que a dominada), observa-se Dominância Estocástica de Primeiro Grau. Observado tal grau de dominância, independentemente da propen- são ao risco do tomador de decisão, a alternativa dominante é estocasticamente preferível à alternativa dominada (Ver SOUZA (1990)).

Portanto a alternativa com ampliação das áreas de aplicação de vinhaça (Desafiante) é estocasticamente preferível à alternativa atual, independentemente do comportamento do tomador de decisão em relação ao risco.

\section{Utilização do Modelo Econômico de Empresa}

$\mathrm{T}$ oda a modelagem matemática utilizada no trabalho de nada serviria, não só para comunidade acadêmica como também para os profissionais da área, sem a ilustração mais precisa da aplicação do modelo e das suas limitações.
Primeiramente analisaremos a utilização do modelo econômico de empresa em usinas de açucar e álcool e, posteriormente, utilizando o modelo como um sistema de apoio a decisões para análise econômica de projetos de $\mathrm{P} \& \mathrm{D}$, em um centro de tecnologia do setor sucroalcooleiro. 


\section{Processo decisório em Usinas de Açúcar e Álcool}

Antes de tudo, devemos caracterizar o processo decisório de uma usina de açúcar e álcool, classificando o que denominamos de decisões de caráter estratégico e decisões de caráter operacional.

Alguns autores, como por exemplo ANSOFF (1965), classificam as decisões de caráter estratégico como a relação da empresa com o meio externo, mais especificamente, o mercado; sendo que por meio dela se define qual é o negócio da empresa e quais suas outras possíveis oportunidades. As decisões citadas no artigo como estratégicas se enquadrariam mais adequadamente entre as que Ansoff denomina de decisões de caráter administrativo, relacionadas com a estrutura de recursos da empresa. Já BUFFA (1985) cita que os seis mais importantes componentes de uma estratágia de manufatura são:

1- Posicionamento do Sistema de produção;

2- Decisões de Capacidade e Localização;

3- Tecnologia de processo e produto;

4- Projeto da força de trabalho;

5- Implicações estratégicas de decisões operacionais;

6- Integração vertical e com fornecedores;

Com relação às decisões de caráter operacional, para ANSOFF (1965), são decisões que maximizam a eficiência da utilização de recursos. Na literatura são citadas, como exemplos mais importantes, decisões operacionais: alocação de recursos, programação de operações, monitoramento de desempenho e aplicação de técnicas de controle. Para o trabalho, temos:

Decisões de caráter estratégico são aquelas que fazem parte do plano estratégico inicial; no caso de uma usina, são decisões que alteram a estratégia inicial definida para uma safra. São exemplos de decisões de caráter estratégico em uma usina:

decisão de implantação de uma nova unidade industrial de aproveitamento de um sub-produto, gerando novos produtos. decisão de ampliação da capacidade de moagem.

decisão de mecanização da colheita.

decisão de renovação de caminhões de transporte de cana.

decisão quanto à automação de determinado processo produtivo.

decisão quanto ao perfil de variedades nas fazendas da usina.

decisão referente ampliação a capacidade de aplicação de vinhaça na lavoura.

Todas essas decisões são tomadas tipicamente no início de safra, definindo o que chamamos de estrutura física da usina; na maioria das vezes, tais decisões envolvem uma alteração no custo direto e fixo de produção (custo de equipamentos, instalações,....).

Decisões de caráter operacional são as decisões do denominado dia-a-dia da empresa. São decisões que pressupõem uma estrutura física inicial da usina, definida por um planejamento de caráter estratégico. São decisões que administram a utilização de recursos e mão-de-obra, pressupondo-se que não haverá alteração na estrutura física da empresa. São exemplos de decisões de caráter operacional:

definição de um planejamento de colheita das fazendas da usina;

alocação de máquinas agrícolas para operações de plantio;

deslocamento de frentes de corte entre fazendas;

programação diária do transporte de cana;

alteração do mix produtivo (açúcar/ álcool) em determinado dia, em função de impurezas da matéria prima (cana-deaçúcar).

A utilização do modelo econômico de empresa é destinada a apoiar decisões de caráter estratégico, definindo a rentabilidade econômica da empresa como um todo, ou em pequenas áreas de negócios; de tal forma que o empresário consiga, com poucos indicadores, ter informações do desempenho econômico de cada área específica. Uma questão importante a ser mencionada referese à eventual relação deste modelo com os 
sistemas de informações das usinas, inclusive sistema de apoio a decisões de caráter técnico, como por exemplo, um planejamento de colheita. A figura 13 ilustra a relação com os sistemas de informações gerenciais da usina.

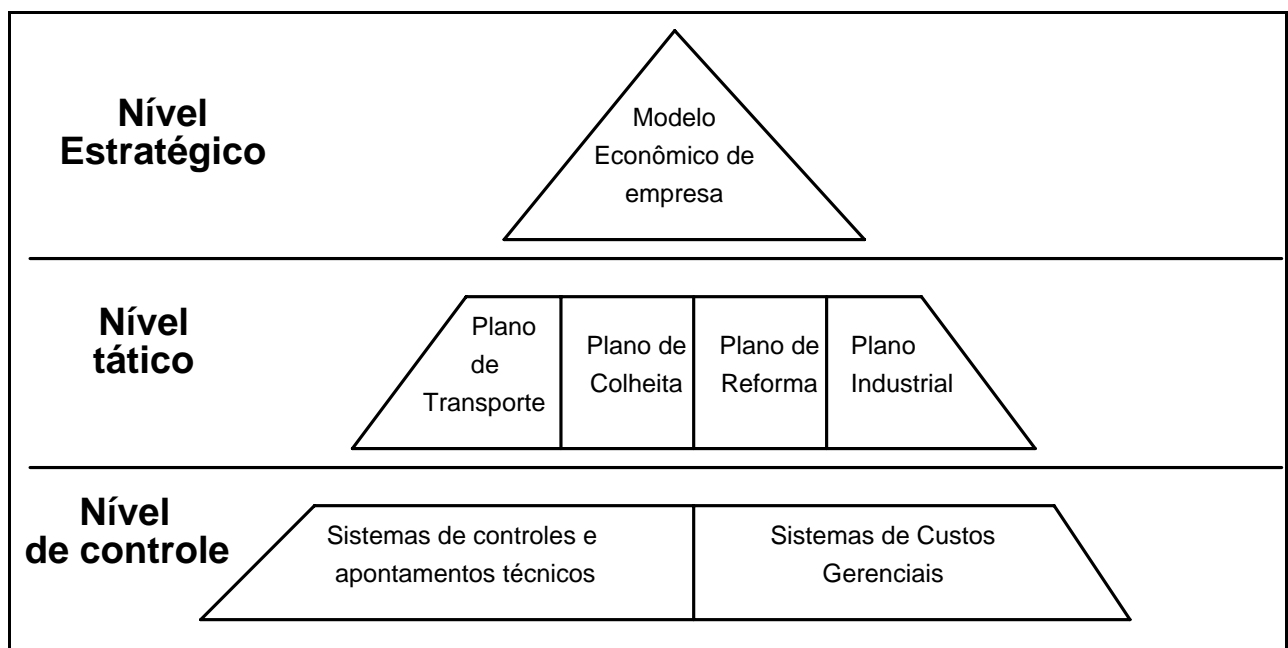

Figura 13 - Relação do modelo econômico de empresa com os sistemas de informação, nos níveis operacional tático e operacional de controle.

Muito provavelmente chegará o dia em que um modelo econômico de empresa estará completamente integrado com todos os outros sistemas de informação gerenciais das usinas, permitindo obter tais análises no nível estratégico com uma grande facilidade, determinando os denominados "gargalos econômicos” da usina, sob a óptica da teoria da decisão.

\subsection{Utilização do Modelo Econômico de Empresa como auxílio em projetos de P\&D}

Como analisar economicamente um projeto de $\mathrm{P} \& \mathrm{D}$ aplicado a processos produtivos?

Com certeza esta pergunta é extremamente complexa para ser respondida; citaremos apenas algumas questões relativas à eficácia (atingir objetivos) e à eficiência (otimização da alocação de recursos) em um projeto de $\mathrm{P} \& \mathrm{D}$.

Variáveis de incerteza relacionadas com a eficácia de um projeto de P\&D:

Mercado - incerteza com relação à utilização da tecnologia pelo setor produtivo, na fase de transferência de tecnologia.

Mercado - incerteza na estimativa de benefícios em usinas, em face do complexo e incerto processo produtivo de uma usina de acúcar e álcool.

Variáveis de incerteza relacionadas com a eficiência de um projeto de $\mathrm{P} \& \mathrm{D}$ :
Incerteza na estimativa do prazo de desenvolvimento

Incerteza na estimativa de recursos

Em situações de tamanha incerteza, elementos da teoria da decisão podem ser bastante úteis no auxílio ao processo de tomada de decisões, principalmente relacionado com a rentabilidade econômica de um empreendimento.

Um outro aspecto que nos parece bastante interessante na gestão de projetos de $P \& D$ é a possibilidade de gerenciar Portfólios de projetos, verdadeiras carteiras de investimento compostas por projetos. Para sermos um pouco mais claros, utilizaremos inclusive um exemplo simples. Quando, com nossas economias pessoais, decidimos aplicar um pouco em poupança (Risco zero), um pouco na bolsa de valores e um pouco em um consórcio para um carro, na verdade 
estamos elaborando uma carteira de investimento, balanceando rentabilidade de curto, médio e longo prazo. É exatamente nesse sentido que acreditamos ser possível uma avaliação econômica de um projeto de $\mathrm{P} \& \mathrm{D}$, analisando um conjunto de projetos, não somente quanto à rentabilidade, mas também quanto ao risco e à liquidez. $\mathrm{Na}$ literatura especializada em assuntos financeirios são mencionados alguns modelos, como o CAPM (Capital Asset Pricing Model), que se inclui entre os pertencentes ao estudo a que FRANCIS (1988) deu nome de Teoria do Portfólio.

Como poderia ser útil o modelo econômico de empresa sucroalcooleira para a Gestão de projetos de P\&D de processo? A resposta está na determinação da eficácia de um conjunto de projetos de P\&D. O alvo de todas as tecnologias desenvolvidas deve ser o sistema produtivo, com todas as suas incertezas. No caso do setor sucroalcooleiro, a linha de produção de usinas. Pois bem, não é exatamente isso o que se propõe o modelo econômico de empresa: determinar o impacto econômico de novas tecnologias na linha de produção?

Neste caso, para determinarmos tal rentabilidade, deveríamos quantificar algumas variáveis de algumas usinas, que poderiam ser denominadas como Usinas Padrão, e analisar o efeito econômico de cada portfólio de projetos de P\&D na cadeia produtiva como um todo, quantificando o benefício da tecnologia, como fez a CEPLAC (Comissão Executiva dos Plantadores de Cacau) no caso do cacau. PIZYSTEZNIG (1987).

A CEPLAC é um centro de tecnologia que, entre outras funções, desenvolve, novas tecnologias para o processo produtivo do cacau, localizado em Ilheus-B.A. Por meio de um modelo econômico, chegaram à conclusão de que o "gargalo econômico" do processo estava no transporte da matériaprima das fazendas até a unidade de produção. O mais surpreendente é que a maioria das pesquisas estava sendo realizada na quebra da casca do cacau e no seus processos de extração. Iniciaram uma nova linha de trabalho para o desenvolvimento de novas tecnologias para a atividade de transporte do cacau.

\section{Considerações finais}

Apresentamos no presente trabalho uma metodologia que aborda aspectos que julgamos bastante relevantes no agribusiness moderno:

1. Abordagem Sistêmica da cadeia produtiva.

2. Analisa economicamente um investimento na cadeia produtiva.
3. Utiliza elementos da Teoria da Decisão sob condições de incerteza

Com base nesta abordagem o trabalho sugere duas utilizações para o presente modelo: Sistema de apoio a decisões de caráter estratégico e um modelo para a determinação da eficácia de programas de P\&D aplicados a processos.

\section{Referências Bibliográficas:}

ANSOFF, H. I.: Corporate Strategy - Business Policy for growth and expansion. McGrawHill Book Company, New York, 1965.

BRUNSTEIN, I.: "Uma proposta de modelagem econômica de processos químicos com produção de produtos conjuntos”. In: Anais do 10 Congresso Brasileiro de Engenharia Química, EPUSP - São Paulo, p.1149-1154, 1994.
BUFFA, E.: “Meeting the Competitive Challenge with Manufacturing Strategy", National Productivity Review, Spring 1985.

FRANCIS, J. C.: Management of investments. Bernard M.Baruch College, City University of New York, 1985.

HOLLOWAY, C.: Decision Making under Uncertanties. Prentice-Hall International, Inc., London, 1979. 
HADAR, J. \& RUSSEL, W. R.: "Rules for ordering uncertain prospects" American Economic Review, Ithaca, 59:25-34, 1969.

GARCIA, J. C. \& CRUZ, J. C.: "Seleção pela dominância estocástica de práticas agrícolas eficientes com respeito ao Risco, uma aplicação para a cultura do milho" Revista Economia Rural, Brasilia, 17(2), abr./jun. 1979.

PACHECO, J. A. C.: Modelos de decisão na análise econômica de experimentos agrícolas. Dissertação (Mestrado), ESALQ - Escola Superior de Agricultura "Luiz de Queiroz” - USP, Piracicaba, 1985.

PIZYSIEZNIG FILHO, J.: Um modelo de avaliação de novas tecnologias: $O$ caso do aproveitamento dos sub-produtos do cacau. Dissertação (Mestrado), ESALQ - Escola Superior de Agricultura "Luiz de Queiroz", USP, Piracicaba, 1987.
SHIMIZU, T.: Simulação em computador digital. Editora Universidade de São Paulo, São Paulo, 1975.

SHIMIZU, T.: Pesquisa Operacional em engenharia, economia e administração Modelos básicos e métodos computacionais. Editora Guanabara Dois, Rio de Janeiro, 1984.

SOUZA, F. D. B.: Dominância estocástica versus estabilidade na seleção de Genótipos. Dissertação (Mestrado), Departamento de Economia e Sociologia Agrícola, ESALQ - Escola Superior de Agronomia “Luiz de Queiroz”, USP, Piracicaba, 1990.

\section{Bibliografia Complementar:}

COPERSUCAR (Cooperativa dos Produtores de Açúcar e Álcool do Estado de São Paulo Ltda): Proálcool fundamentos e perspectivas. Área Central de Planejamento e Economia, 1989.
SPERANDIO, O.: Uma contribuição à contabilidade de custos de produtos de origem canavieira. Dissertação (Mestrado), Departamento de Contabilidade e Atuária, Faculdade de Economia e Administração USP, São Paulo, 1990.

\section{ECONOMIC MODEL FOR A SUGARCANE COMPANY}

\section{Abstract}

This work describes an Economic Model for a Sugarcane Company. The model was adapted from the Economic Model of a Company with process of conjuct process. In addition, we present the utilization of Simulation Systems, and the analysis of the output was based in Stochastic Dominance criteria.

Key-words: economic model of company, agribusiness, decision theory under uncerntanties, economic analysis, system simulation. 